\title{
OTROS ESTUDIOS
}

\author{
Fernando Berríos
}

Universidad Católica del Norte - Coquimbo

\section{El método antropológico-trascendental de Karl Rahner como hermenéutica teológica del mundo y de la praxis (1)}

En torno a la conmemoración del $40^{\circ}$ aniversario del Concilio Vaticano II (1962-1965), la teología ha estado retomando sus intuiciones y enseñanzas fundamentales para valorar su recepción en el pensamiento y en la praxis eclesiales, o bien para asumir con espíritu renovado el desafío de apropiárselas y de proyectarlas en el caminar de los cristianos. El tema que aquí nos ocupa se inscribe en la misma motivación básica: como una reflexión en sintonía con la constitución Gaudium et spes y su doctrina sobre la actividad humana en el mundo, con el reconocimiento de su justa autonomía a partir del principio de la bondad radical del mundo, y de su sentido humano y salvífico en el horizonte escatológico de la historia de la humanidad (GS 33-39). Recogiendo el espíritu del concilio, en las siguientes páginas se intentará hacer un aporte a una reflexión que ayude a los cristianos a valorar su caminar por la historia con un sentido de solidaridad con el mundo en que están insertos y de corresponsabilidad en su construcción mediante su concreta praxis, entendida como respuesta de la libertad humana interpelada por el Dios que actúa en la historia y desde ella. La reflexión sobre la praxis en la perspectiva de la teología trascendental de Karl Rahner se ubica precisamente en ese horizonte (2).

El propósito central de las siguientes páginas es bosquejar una reflexión acerca del método antropológico-trascendental de Karl Rahner como camino para una lectura teológica de la realidad y para la comprensión creyente del sentido de la praxis humana; de su intuición fundamental (acápite 1.), de sus principales contornos como método teológico para la comprensión de la realidad (acápite 2.) y del sustrato

(1) El presente artículo es -junto con mi anterior estudio "Teología trascendental y praxis. Una reflexión desde el legado de Karl Rahner", Teología y Vida, Vol. XLIII (2002) 467-502- resultado de una investigación iniciada en la Universidad de Tübingen, Alemania, en el semestre de invierno 2000-2001, con el apoyo de la Alexander von Humboldt-Stiftung y del Consejo de Perfeccionamiento de la Universidad Católica del Norte, y luego continuada en Chile durante 2002 y parte de 2003 con el patrocinio de Stipendienwerk Lateinamerika-Deutschland, e.V., a través de su Consejo de Valparaíso.

(2) Mi artículo "Teología trascendental y praxis", recién citado, ofrece una descripción de los contornos generales de la temática de la praxis en el pensamiento de K. Rahner y una reflexión sobre ella a partir de las aplicaciones que el autor hace del enfoque trascendental a diversas temáticas teológico-sistemáticas. 
filosófico en que se basa (acápite 3.), para finalmente analizarlo a la luz de una suerte de comparación con la antropología trascendental de otro autor relevante en esta perspectiva, el filósofo francés Maurice Blondel (1861-1949), célebre por el desarrollo del enfoque trascendental a partir de una "ontología de la acción”. Con esta somera confrontación pretendo aportar a un mayor esclarecimiento de la opción de Rahner por fundar su antropología trascendental en una "metafísica del conocimiento", para, a partir de allí, entender mejor el sentido y las posibilidades de una mirada teológico-trascendental de la praxis. Desde esta misma reflexión se hará alusión a algunos alcances críticos a la perspectiva trascendental rahneriana.

\section{EL “GIRO ANTROPOLÓGICO” DE LA TEOLOGÍA SEGÚN RAHNER}

Un aspecto fundamental del pensamiento teológico de Karl Rahner fue su convicción de que la dogmática toda debía devenir una antropología teológica. Para él esto debía constituir un auténtico "giro" (Wendung), un vuelco "necesario y fecundo" de la teología (3). Para describirlo, utilizó expresiones no poco audaces que pusieron de manifiesto el carácter definitivamente "antropocéntrico" -y ya no solo "antropológico"- que él asignó a tal giro, y que no dejan lugar a dudas sobre la radicalidad de su planteamiento. Para Rahner el tema del hombre no ha de ser considerado como uno más entre otros, sino como la cuestión que debe dominar "el conjunto" (das Ganze) de la teología dogmática (4).

En esta comprensión de la teología es básica la convicción de que no hay una oposición real entre lo "teocéntrico" y lo "antropocéntrico", dado que lo antropológico, el ser humano en cuanto tal o "por naturaleza", es concebido como "el ser de la trascendencia hacia el mundo (zu Welt) y hacia Dios ( $z u$ Gott)", trascendencia que se traduce en su esencial y definitiva apertura. La comprensión del hombre como esencialmente "abierto" es la base de este, para Rahner, necesario giro de la teología, pero además es lo que le permite distanciarse del peligro de una mera reducción antropológica de la misma. Puesto que el hombre está, en tal visión, esencialmente referido a Dios y dado que, por otra parte, él no puede decir absolutamente nada de este Dios fuera de la posibilidad -gratuitamente recibida- de una tal referencia esencial, lo antropocéntrico y lo teocéntrico, bien entendidos, no son -ni podrían ser- conceptos opuestos en la teología cristiana (5).

(3) Los trabajos de K. Rahner contenidos en sus Schriften zur Theologie, 16 volúmenes, EinsiedelnZürich-Köln 1954-1984, se citarán del siguiente modo: nombre del artículo entre comillas (abreviado si es recurrente), abreviatura $S T h$, volumen en número romano y páginas citadas. Aquí: "Theologie und Anthropologie", STh VIII, 43-65. (Al citar las obras de Rahner no se explicitará su autoría, salvo cuando sea estrictamente necesario para la claridad de la referencia.) Acerca de la importancia que llegaría adquirir esta impronta antropológica en la elaboración de los documentos del Concilio Vaticano II, cf. J. Heiner Tück, "40 Jahre Zweites Vatikanische Konzil. Vergessene Anstösse und Perspektiven", Theologie und Glaube, Vol. 93 (2003) 48-59, esp. 58 s.

(4) Me refiero a expresiones como "anthropozentrische Wendung" o "anthropozentrik der Theologie"... (Loc. cit.). Cf. K. W. Berenbruch, "Der anthropologische Ansatz Karl Rahners", Theologische Versuche 6 (1975), 137-155.

(5) Cf. K. Lehmann, "Karl Rahner. Ein Porträt", en: K. Lehmann - A. Raffelt (eds.), Rechenschaft des Glaubens. Karl Rahner-Lesebuch, Freiburg i. Br. 1979, 13*, 53*, 35*s. Sobre el 
Por lo mismo, menos aun puede haber en tal perspectiva una oposición entre este "centramiento antropológico de la teología" (6) y el necesario centramiento cristológico de la misma. Bien entendidas, antropología y cristología se sostienen mutuamente en la dogmática cristiana, por cuanto una antropología solo puede ser cristiana si en ella el hombre es concebido como "potentia oboedientialis para la "unio hypostatica"” y, por su parte, la cristología, para evitar toda sospecha de una lectura mitologizante de dicha unión -como ocurriría en una cristología meramente aposteriorística-, requiere de la comprobación de un "horizonte trascendental en el ser agraciado del hombre y de su historia para la idea del hombre-Dios" (7).

Este "enfoque antropológico" (anthropologischer Ansatz) se aplica ciertamente a la dimensión individual-subjetiva del encuentro humano con Dios que se autocomunica, pero no menos a la dimensión intersubjetiva (estructural-social, comunitaria) de tal acontecimiento, la cual influye y se manifiesta de un modo decisivo en la concreta autorrealización de la Iglesia y, con ello, en la realización de su función sacramental de la salvación en cada momento de su despliegue histórico (8). Esto aparece así a partir de la convicción cristiana de que el destinatario de dicha misión mediadora de la Iglesia, que es el ser humano, la humanidad, tiene como una "determinación fundamental" (Grundbestimmung) el ser, concretamente, "cohumanidad" (Mitmenschlichkeit) histórica (9).

Pero ¿por qué postular con tanto vigor este giro antropológico? Tres son básicamente los motivos que, para Rahner, lo hacen, en definitiva, "necesario" (10). En primer lugar, un motivo que surge desde la teología misma y su objeto: el hecho de que en ella, como en todo conocimiento "espiritual", la pregunta por el objeto es también necesariamente pregunta por el ser del "sujeto cognoscente", porque este "debe traer consigo apriorísticamente el horizonte de la posibilidad de un tal conoci-

enraizamiento de esta intuición básica en la experiencia espiritual ignaciana de K. Rahner y su esfuerzo de "traducir" ello filosóficamente en un "horizonte de comprensión actual" y, más exactamente, en una "ontología existencial actual", $c f$. K. P. Fischer, "Gott als das Geheimnis des Menschen. Karl Rahners theologische Anthropologie-Aspekte und Andfragen", Zeitschrift für katholische Theologie 113 (1991) 1-23.

(6) "Anthropologische Zentrierung der Theologie" (= centramiento antropológico de la teología), que es otra de las expresiones elegidas por Rahner para describir este giro ("Theologie und Anthropologie", 43).

(7) Ibid., 43s

(8) Cf. Anthropologische Voraussetzungen für den Selbstvollzug der Kirche, en Karl Rahner: Sämtliche Werke (en adelante $S W$ ), Bd. 19: "Selbstvollzug der Kirche: Ekklesiologische Grundlegung praktischer Theologie", K. Neufeld (ed.), Düsseldorf-Freiburg i.Br. 1995, 181-196. En este volumen se han reunido todos los aportes de nuestro autor a la obra colectiva en que él actuó además como editor, junto a H. Schuster: Handbuch der Pastoraltheologie, Freiburg 1964 (vol. I), 1966 (vol. II), 1968 (vol. III), 1969 (vol. IV), 1972 (Vol. V: Lexikon der Pastoraltheologie).

(9) Ibid., 191 s. Sobre este aspecto, recomiendo el sugerente artículo de B.-D. de La Soujeole, "Le débat sur le surnaturel et l'ecclésiologie contemporaine", Revue Thomiste 101 (2001) 329-343 ("... es necesario incluir la perspectiva de la caridad para comprender cabalmente el sobrenatural. Ella abarca una multitud de personas creadas, y no pasará... Hay una vida humana de gloria hecha de interacciones humanas inseparables del acto primero de la beatitud [visio beatifica]..., es la integralidad de la naturaleza la que es intrínsecamente agraciada y glorificada”: p. 343).

(10) Cf. "Theologie und Anthropologie", 49-61. 
miento" (11). Y dado que Dios no es un objeto entre otros en el ámbito de la experiencia aposteriorística del ser humano, sino "el fundamento originario y el futuro absoluto de toda la realidad", solo puede ser concebido en la teología como el norte o destino absoluto (das absolute Woraufhin) de la trascendentalidad del hombre. Y una teología así entendida y enfocada es, pues, necesariamente una "antropología trascendental". Lo dicho se aplica a la noción cristiana misma de Revelación, por cuanto esta comporta, como "momento interno y condición de posibilidad" de su acogida por parte del hombre, el "horizonte trascendental-ilimitado del espíritu humano" (12).

A esta índole "trascendental" del centramiento antropológico de la teología aquí postulado y a las implicancias para la comprensión de su engarce con la filosofía, habrá que referirse luego más detenidamente; pero hemos de consignar que el segundo motivo que Rahner esgrime para justificar la necesidad de dicho vuelco es, precisamente, su fuerte convicción de ser parte de una "situación epocal" en que tanto para la filosofía como la teología no es ya posible dar pie atrás del giro trascendental-antropológico de la filosofía moderna, acontecido "desde Descartes, Kant, pasando por el idealismo alemán (...) hasta la fenomenología, la filosofía existencial y la ontología fundamental" (13) que, sabemos, el jesuita conoció directamente de Martin Heidegger durante el tiempo de sus estudios de filosofía en la Universidad de Freiburg.

Pero lo relevante en este punto es el hecho de que el hombre de fe Rahner no solo conoce bien todo este movimiento filosófico, sino que además se deja interpelar por él y por lo que reconoce como su intuición central. Aunque asume estar hablando de una corriente de pensamiento en cierto sentido "profundamente no cristiana" (unchristlich) en cuanto "filosofía trascendental del sujeto autónomo" (14), la reconoce por otra parte como "profundamente cristiana", porque, para él, en un cristianismo radical el hombre no es "un momento dentro de un mundo (Kosmos) de cosas", sino "el sujeto de cuya libertad subjetiva depende el destino de todo el cosmos" (15). De otro modo, la historia de salvación o de condenación no tendría significación cosmológica alguna, ni podría captarse el verdadero alcance de una cosmología cristológica. Es esta perspectiva antropológica fundamental la que Rahner reconoce, precisamente, como aporte característico y definitivo de la filosofía moderna que la teología no puede soslayar, aun cuando algunos de sus contemporáneos sostuvieran ya la para él al menos discutible tesis del "fin de la modernidad". A su parecer, aun cuando se aceptara la apreciación de estar en una época "postmoderna" o en la configuración de una nueva "forma epocal", el giro (Wendung) hacia una antropología trascendental persiste como "una exigencia a la teología de hoy y de mañana" (16).

(11) Ibid., 50 .

(12) Todas estas expresiones, en Ibid., 50s.

(13) Ibid., 56.

(14) Aunque destacando explícitamente a Maurice Blondel y su perspectiva trascendental como una excepción a tal consideración.

(15) Loc. cit.

(16) Cf. ibid., 57, nota 19, con una referencia explícita a R. Guardini, Ende der Neuzeit, Würzburg 1950 . 
El tercer motivo esgrimido por Rahner para fundamentar la necesidad de esta orientación antropológica de la teología, brota de la necesaria determinación "teológico-fundamental-apologética" de la teología. Se trata de aquella dimensión esencial de la teología en cada contexto histórico-cultural, que consiste en descubrir e iluminar la relación interna o correspondencia fundamental entre el contenido de las afirmaciones dogmáticas de la doctrina cristiana y la experiencia que de sí mismo (Selbsterfahrung) hace concretamente el ser humano. Si esta relación no se descubre, muchas afirmaciones teológicas se tornarán incomprensibles y, con ello, difícilmente susceptibles de recibir un verdadero asentimiento de fe.

Por todo lo dicho, para Rahner la referida determinación debe ser realizada concretamente como un "giro imperativo hacia un método trascendental-antropológico en la teología” (17). A ello nos referiremos a continuación.

\section{EL MÉTODO TRASCENDENTAL COMO HERMENÉUTICA TEOLÓGICA DE LA REALIDAD EN APERTURA A LA MODERNIDAD}

Lo recién señalado podría formularse también desde esta otra perspectiva: el necesario giro antropológico de la teología tiene en el planteamiento de Rahner un carácter específicamente "trascendental", el cual determinará a su vez el método de su quehacer teológico.

Hemos constatado que el uso de esta terminología y, sobre todo, el enfoque básico que comporta, reflejan una actitud fundamental de Rahner de apertura a la cultura moderna y su consecuente esfuerzo por formular los contenidos fundamentales del cristianismo en categorías filosóficas relevantes para sus contemporáneos, por considerar ello un desafío ineludible para la teología y para las ciencias del espíritu en general a partir del vuelco antropológico acaecido y afianzado en el pensamiento filosófico de la modernidad. Pero si la perspectiva general de la teología se abre con ello a un giro o recentramiento "antropológico", la comprensión propiamente teológico-trascendental de dicha antropología refleja, por otra parte, con nitidez la convicción cristiana básica de que la revelación y la salvación, aun cuando atañen al hombre, son ante todo un acontecimiento de la iniciativa divina. Un acontecimiento (Ereignis) que se da en el hombre, con el hombre y desde del hombre, pero que es primero y fundamentalmente obra de Dios (18). La perspectiva trascendental de Rahner toca por ello, en cuanto aproximación teológica, al modo de proceder salvífico de Dios para con el ser humano, de tal manera que este pueda reconocerlo y experimentarlo.

(17) Ibid., 61. El destacado en la cita textual es mío.

(18) A la noción rahneriana del hombre como "acontecimiento de la autocomunicación de Dios" y a sus implicancias para la comprensión teológico-dogmática de la gracia, me he referido más extensamente en mi artículo "Teología trascendental y praxis...", citado en la nota 1. La consideración explícita del hombre como "acontecimiento de la absoluta autocomunicación de Dios" (das Ereignis der absoluten Selbstmitteilung Gottes), Rahner la desarrolla, entre otros lugares, en Grundkurs des Glaubens. Einführung in den Begriff des Christentums, en el contexto de la exposición de "la oferta de la autocomunicación (de Dios) como existencial sobrenatural" (IV Gang., $S W$, Bd. 26: "Grundkurs des Glaubens. Studien zum Begriff des Christentums", N. Schwerdtfeger - A. Raffelt (eds.), Düsseldorf - Freiburg i. Br. 1999, 3-445; sobre este punto, 126-128.126.) 


\subsection{La impronta trascendental del método y su aplicación a la praxis}

Ahora bien, ¿cómo expresar este enfoque antropológico de tal manera que el creyente moderno pueda captarlo y hacerlo suyo en una comprensión de la fe cuya relevancia alcance también sus esfuerzos históricos, que él realiza desde la convicción del valor decisivo de su autonomía? Ello nos remite, a su vez, a otra pregunta fundamental: ¿qué entiende exactamente Rahner por esta impronta "trascendental" que va a marcar el método y el enfoque general de su reflexión teológica, y en qué medida y modo ella puede determinar la comprensión cristiana de lo que llamamos "realidad", que no es sino el mundo como desafío, en el acontecer histórico, al despliegue de la praxis?

Por "praxis" entendemos aquí el concreto despliegue de la relación del ser humano con el mundo en cuanto medio y horizonte de las condiciones históricas de su existencia y coexistencia. No interesa en este enfoque entrar en la problemática de la polaridad teoría-praxis, sino, por el contrario, entender por praxis el conjunto de la acción o del quehacer humano en general, ya sea de carácter intelectualespeculativo o más bien poiético; ya sea marcado por una actitud pasiva-defensiva o por una actitud agresiva-transformadora en el mundo en su despliegue histórico. Se entiende aquí, pues, por praxis, la totalidad de lo que el hombre, desde su propia autocomprensión, hace o deja de hacer en su existencia mundana, por cuanto todo ello constituye, de un modo u otro, su concreta manera de habitar el mundo. Siendo su morada, el mundo constituye al mismo tiempo lo distinto del hombre por antonomasia y es por lo mismo un desafío permanente a la acción, o a la reacción, o a la pasiva ausencia de ambas.

Establecido ello, volvamos a la pregunta por el sentido que Rahner da a la impronta trascendental del método de la teología. Hemos constatado que se trata de una noción que Rahner no inventa sino que toma -como parte de un acto para él necesario al quehacer teológico- del giro antropológico operado en la filosofía moderna. Luego tendremos que precisar cuál es el camino concreto que el jesuita alemán recorre para llegar a esta asunción y en qué medida y forma esa tradición marca su pensamiento. Por ahora es necesario aclarar qué comporta en lo concreto esta índole trascendental del método en el contexto de su programa de recentramiento antropológico de la teología (19). En lo fundamental -y sin ahondar por el mo-

(19) “Überlegungen zur Methode der Theologie" (en adelante, "Überlegungen”), STh IX, 79-126. Cf. L. Scheffczyk - A. Ziegenaus, Katholische Dogmatik, I. Bd.: "Einleitung in die Dogmatik", Aachen 1997, 236-250, esp. 245-250; L. B. Puntel, "Zu den Begriffen 'transzendental' und 'kategorial' bei Karl Rahner", en H. Vorgrimler (Ed.), Wagnis Theologie. Erfahrungen mit der Theologie Karl Rahners, Freiburg i. Br.-Basel-Wien 1979, 189-198; R. Schaeffler, "Christlicher Glaube und neuzeitliche Subjektivität - Karl Rahner", en G. Lange (Ed.), Glaube denken. Theologische Profile in historischen Stichproben, Hagen 1998, 9-27; Y. Tourenne, "Articulation de la philosophie chez le dernier Rahner" (1969-1984). Approches d'un théologien catholique. Soutenance de la thèse, 4 juin 1993”, en R. A. Siebenrock (Ed.), Karl Rahner in der Diskussion. Erstes und zweites Innsbucker Karl-Rahner-Symposion: Temen - Referate - Ergebnisse, Innsbruck - Wien 2001,159-169; W. Sandler, "Die Kunst des Fragens. Versuch einer systematischen Rekonstruktion von Karl Rahners transzendental-phänomenologischer Methode", en ibid., 247-267. 
mento en su procedencia y trasfondo filosóficos (20)-, para Rahner un planteamiento "trascendental" de una cuestión se da "cuando y en la medida en que se pregunta por las condiciones de posibilidad del conocimiento de un determinado objeto en el sujeto cognoscente mismo".

Esta perspectiva remite a su vez a una comprensión del conocimiento humano según la cual este "no depende solo de las características del objeto, sino también de la estructura esencial del sujeto cognoscente". Por ello, en todo planteamiento trascendental la atención está puesta más bien en la relación mutua o, más exactamente, en la "relación condicionante mutua" (das gegenseitige Bedingungsverhältnis) entre el sujeto cognoscente y el objeto conocido (21).

Lo recién apuntado es de especial importancia para una correcta comprensión del enfoque trascendental postulado por Rahner. No subrayar este interés prioritario por la relación, esto es, por la mutua (gegenseitig) implicancia entre el sujeto cognoscente y el objeto conocido, tendría como consecuencia última -y con especial gravedad en su aplicación estrictamente teo-lógica- una interpretación reductoramente subjetivista de lo que, en la visión rahneriana, acontece en el acto del conocimiento. Por eso él insiste en que "en la relación condicionante mutua entre la subjetividad apriorística, trascendental, y el objeto del conocer (y de la libertad), el conocimiento de las condiciones apriorísticas de la posibilidad del conocimiento en el sujeto significa también un momento del conocimiento del objeto mismo (...) Un planteamiento trascendental de la cuestión no es, por consiguiente, solo una pregunta sobreañadida (zusäztlich) a la pregunta por el objeto que se presenta original y aposteriorística-empíricamente, sino que solo en él el conocimiento del objeto mismo originario alcanza su plenitud (vollen Wesen). El conocimiento del sujeto cognoscente es, de por sí, siempre también un conocimiento de las estructuras metafísicas (en un sentido objetivo de 'trascendentales') del objeto mismo" (22).

\subsection{Dos reparos}

A partir de esta comprensión fundamental de la perspectiva trascendental cabría aquí destacar, además del aspecto recién aludido, dos importantes ámbitos de posibles reparos para una teología así enfocada, de los que el jesuita alemán se hizo consciente: el primero, con respecto a la relación entre trascendencia e historia; y el segundo, con respecto a la relación entre trascendentalidad y gratuidad de la autocomunicación de Dios. Dado que ya me he referido de modo general a estos temas en otro lugar (23), me limito aquí a un par de alcances acerca de la manera como él los recoge específicamente en su presentación del método trascendental en teología.

Con respecto a lo primero -la relación entre trascendencia e historia-: por una parte, para Rahner un planteamiento y método trascendental en teología no conlleva

(20) Sobre tal aspecto, $c f$. infra, acápite 3.

(21) "Überlegungen", 98.

(22) Ibid., 98s. El destacado en cursiva es mío.

(23) Cf. mi estudio "Teología trascendental y praxis" (citado en la nota 1). Sobre la relación entre trascendencia-historia: 482-484; sobre la relación entre trascendentalidad y gratuidad de la autocomunicación divina: 477-481. Allí se encontrarán las necesarias referencias, para ambos aspectos, a la literatura primaria y secundaria. 
en absoluto la pretensión de que el sujeto históricamente situado sea en sí y por sí el acontecer de la plenitud, sino que más bien allí él se percibe a sí mismo, en la índole ilimitada de su trascendentalidad, como una pregunta "abierta" o "vacía", como un "extático estar-referido (Verwiesenheit) a aquello que experimenta como lo que él precisamente no es". Esto, dado que el sujeto experimenta el volver-sobre-sí-mismo (Zusichselberkommen) de su trascendentalidad como mediado por la experiencia aposteriorística del objeto que desde sí se muestra o se resiste y sobre el cual el sujeto no tiene dominio (24). Se trata de una experiencia trascendental de la trascendencia, en el sentido bosquejado más arriba, que empero no llega a anular la diferencia entre el sujeto cognoscente y el objeto de su apertura infinita.

Por otra parte, este salvar la diferencia no implica una devaluación de la historia como espacio ciego de la inmanencia. Lo que Rahner caracteriza como "el retorno del sujeto a las condiciones trascendentales de posibilidad de su conocimiento (y de su libertad)" implica, precisamente por ese movimiento, "la noción de su indefectible estar-referido a la historia" (25). Tal vez el aspecto más característico y más sugerente del enfoque trascendental rahneriano llegó a ser su intuición de una necesaria "mediación histórica entre trascendentalidad y trascendencia" (26). Esta mediación permite, por un lado, evitar una comprensión de la trascendentalidad como realización ahistórica de la autocomunicación de Dios (comprensión que podría subyacer a una cierta noción del a priori); y por otro lado, la idea de que la trascendentalidad y, de este modo, la trascendencia misma acontecen históricamente, abre de manera radical los horizontes de la historia en cuanto tal (27).

El otro aspecto problemático indicado -el de la relación entre trascendentalidad y gratuidad de la autocomunicación de Dios- es inseparable del recién reseñado y toca directamente a la doctrina de la gracia, centro estructurante de la teología rahneriana (28). En lo que se refiere específicamente al método teológico, la intuición central es aquí que "no es legítimo presuponer (...) que un planteamiento trascendental respecto del conocimiento de una determinada realidad deba, por principio o de hecho, 'adelantarse' simplemente en cuanto tal al efectivo conocimiento de este objeto; dado que en este planteamiento de la cuestión siempre se pregunta por las condiciones apriorísticas de posibilidad del conocimiento de una determinada realidad, tal planteamiento es, en consecuencia, práctica y concretamente posible siempre y cuando el objeto referido ha sido ya reconocido (29)". Es decir, el enfoque trascendental parte ya de una determinada experiencia de la autocomunicación de Dios, y no al revés.

Como hemos observado más arriba, la índole trascendental de la autocomunicación de Dios alude a un acontecimiento que se da en, por y para el hombre

(24) "Überlegungen", 99.

(25) Ibid.

(26) "Geschichtliche Vermittlung von Transzendentalität und Transzendenz" (título del $2^{\circ}$ apartado del paso V del Grundkurs des Glaubens..., 139).

(27) Loc. cit. A este aspecto me he referido más extensamente en "Teología trascendental y praxis", 482-484.

(28) Cf. R. Siebenrock, "Gnade als Herz der Welt. Der Beitrag Karl Rahners zu einer zeitgemäßen Gnadentheologie", en: M. Delgado - M.- L. Bachmann (eds.), Theologie aus Erfahrung der Gnade. Annährung an Karl Rahner, Berlin 1994, 34-71. "Überlegungen", 102. 
históricamente situado, pero que es ante todo un obrar de Dios mismo. En consecuencia, el carácter trascendental de la autodonación salvífica de Dios no merma en absoluto la radical gratuidad de esta ni llega siquiera a opacar la distinción real entre el Dios que se autocomunica y el hombre agraciado por esta acción divina. En su nivel más radical -explica Rahner-, "la escucha (Hören) de la revelación de Dios como palabra de Dios mismo (...) presupone como condición de posibilidad en el sujeto el que Dios mismo comparte (mitträgt), por su propia autocomunicación, como principio interno, el acto de tal escucha, y precisamente esto es lo que se ha dado en llamar gracia sobrenatural de la fe (übernatürliche Glaubensgnade) (30)".

\subsection{Método trascendental - praxis - libertad - historicidad}

Recapitulando, lo que Rahner postula como "método trascendental-antropológico en la teología" (31) es relevante para una hermenéutica teológica de la praxis, ante todo porque comporta una comprensión fundamental de la revelación y de la salvación como acontecimiento de la definitiva y absoluta autocomunicación de Dios en y por el hombre en cuanto ser históricamente situado. Sin comprometer ni poner en duda el carácter gratuito de esta autocomunicación divina, ni la diferencia real y necesaria entre Dios y el hombre, la realidad humana toda, en su radical mundanidad e historicidad, aparece como el ámbito único de dicho acontecimiento y de la posibilidad misma de su reconocimiento por parte del ser humano así agraciado.

Esto implica a su vez la convicción de que la autocomunicación de Dios, en cuanto acontecimiento antropológico-trascendental, es también necesaria e inseparablemente un acontecimiento categorial. Tal convicción permite distanciar el enfoque trascendental rahneriano de una comprensión meramente subjetivista, ahistórica e inmanentista de la revelación y la salvación. La fe cristiana tiene como centro y vértice precisamente un acontecimiento histórico, el acontecimiento de Cristo. La perspectiva trascendental, correctamente comprendida, no relativiza este hecho, sino, muy por el contrario, busca captarlo en toda su profundidad. Lo trascendental, como hemos observado, acontece históricamente. Y por el otro lado, la dimensión categorial de este mismo acontecimiento se basa en y es posible por el hecho decisivo y previo de las condiciones apriorísticas-trascendentales de posibilidad (y, por cierto, gratuitas) de un tal acontecimiento.

Ello implica, por otra parte, necesariamente la convicción de que Dios salva al hombre con el concurso de este, de su libertad históricamente situada, y nunca sin ese concurso. Este método trascendental-antropológico desafía, pues, radicalmente a una mirada teológica de la realidad que se haga cargo de la problemática de una auténtica afirmación de la autonomía del sujeto frente a Dios como el objeto de su apertura infinita, y ello en su indefectible articulación histórica. En el ámbito de la praxis se juega para los cristianos el punto decisivo de la salvación como acontecimiento de libertad (32). La intuición teológica de fondo es bíblica, pero en Rahner

(30) Ibid., 103.

(31) "Theologie und Anthropologie", 61.

(32) Sobre el principio rahneriano: "salvación no operada con libertad no puede ser salvación" (Grundkurs des Glaubens, 145), cf. mi artículo "Teología trascendental y praxis", 479-481 
adquiere además, claramente, los rasgos de una conceptualización sensibilizada al pensamiento moderno. Por eso, él llega a reconocer que tras su enfoque trascendental late la presencia de una filosofía trascendental, si bien en un sentido amplio de la expresión (33).

\section{TRASFONDO FILOSÓFICO DE LA ANTROPOLOGÍA TRASCENDENTAL DE RAHNER}

\subsection{Antecedentes biográficos}

¿De dónde surge este enfoque antropológico-trascendental? A decir verdad -y esto es especialmente interesante-, en el joven Rahner ello procedió básicamente del influjo de determinadas perspectivas filosóficas modernas a las que él se abrió desde la tradición escolástica en la que había sido formado, y más exactamente, a través de un profundo redescubrimiento de Tomás de Aquino siguiendo una senda trazada por otros (34).

Todos los conocedores de Rahner y él mismo en un par de entrevistas concedidas en los últimos años de su vida, han destacado la especial importancia que tuvieron para el desarrollo de su pensamiento la lectura de la obra filosófica del jesuita belga Joseph Maréchal (1878-1944) El punto de partida de la metafísica. Lecciones sobre el desarrollo histórico y teórico del problema del conocimiento (35), durante el tiempo de su formación filosófica entre 1924 y 1927, y el período de estudios para un doctorado en filosofía en la Universidad de Freiburg entre los años 1934 y 1936. Habiendo sido destinado tempranamente por sus superiores jesuitas a desempeñarse como profesor de filosofía al interior de su Orden, Karl Rahner fue aceptado en Freiburg como doctorando de Martin Honecker, pero paralelamente siguió cursos y seminarios con el ya afamado Martin Heidegger, quien a la postre dejaría, claramente, una más profunda huella en el joven jesuita.

Una serie de circunstancias, pero al parecer especialmente las fuertes diferencias de enfoques filosóficos entre Heidegger y Honecker, culminaron con el rechazo, por parte de este último, de la tesis de grado de Rahner -ciertamente más

(acápite 2.2 "Trascendentalidad de la gracia - libertad - praxis") y 484 s (acápite 3.2 "Historia de la salvación como historia de libertad").

(33) Cf. "Überlegungen", 100 s. Cf. K. Lehmann, "Karl Rahner. Ein Porträt”, 30*-33*, esp. 31*.

(34) Dentro de una abundante literatura sobre este aspecto del pensamiento rahneriano, destaco: el ya citado trabajo de R. Schaeffler, "Christlicher Glaube und neuzeitliche Subjektivität..."; K. Lehmann, "Karl Rahner. Ein Porträt", 29*-36*; Id., "Philosophisches Denken im Werk Karl Rahners", en: A. Raffelt (ed.), Karl Rahner in Erinnerung, Düsseldorf 1994, 10-27; E. Coreth, "Philosophische Grundlagen der Theologie Karl Rahners", en: Stimmen der Zeit 212 (1994) 525536; E. Bautista Lucas, "Fundamentos filosóficos de la teología de K. Rahner", Efemérides Mexicana 43 (1997) 29-42; M. Chojnacki, "Erhelende Rückführung. Über das Ergreifen Karl Rahners Theologie mittels ihres philosophischen Hintergrunds“, en R. Siebenrock (ed.), Karl Rahner in der Diskussion. Erstes und zweites Innsbrucker Karl-Rahner-Symposin: Themen - Referate Ergebnisse, Innsbruck-Wien 2001, 171-188.

(35) Le point de départ de la métaphysique. Leçons sur le développement historique et théorique du problème de la connaissance, 5 tomos, Bruselas-Paris, a partir de 1922. 
influida por las intuiciones del autor de Sein und Zeit- (36), que años más tarde sería publicada bajo el título Espíritu en el mundo: Acerca de la metafísica del conocimiento finito en Tomás de Aquino (37). Esta obra consiste, como bien lo ha sintetizado Albert Raffelt, en "una interpretación especulativa de la metafísica tomista del conocimiento, influenciada por los trabajos de Joseph Maréchal referidos a los planteos de Kant, y llevada a cabo a la luz del pensamiento heideggeriano de los años veinte y los primeros de la década del treinta" (38). Esto que aparece como la descripción general del marco referencial filosófico del pensamiento de Rahner en un momento fundante, merece ser explicado con mayor detención para mejor comprender la constitución final de su enfoque trascendental.

\subsection{El punto de partida: la metafísica tomasiana del conocimiento}

El punto de partida de Geist in Welt es la metafísica del conocimiento humano en el pensamiento del más importante exponente de la escolástica medieval. De esta tradición proviene Rahner y en ella se inscribe su formación sistemática en filosofía y teología (39). Ello es algo que lo marcará profundamente y en lo cual permanecerá siempre en lo fundamental, aun cuando su espíritu inquieto y especulativo lo lleve a abrirse a otras corrientes, siempre en la dinámica de una profundización de estas sus intuiciones más hondas y permanentes.

En este nivel de su pensamiento la convicción básica es el principio escolástico-tomasiano de la identidad de conocer y ser. El propósito fundamental de Geist in Welt es precisamente mostrar que el conocimiento humano está abierto, en cuanto el hombre es "espíritu", a lo meta-físico, si bien ello acontece solo en y mediante el "mundo", entendido aquí concretamente como "la realidad que es asequible para la experiencia inmediata del ser humano" (40). Rahner basa esta convicción fundamental en la doctrina tomasiana de la permanente referencia del intelecto a la apariencia sensible, conocida como la doctrina de la conversio intellectus ad phantasma (41),

(36) Cf. P. Imhof - H. Biallowons [eds.], Glaube in winterlicher Zeit. Gespräche mit Karl Rahner aus den letzten Lebensjahren, Düsseldorf 1986, 49; A. Raffelt-H.Verweyen, Karl Rahner, München 1997, 13-16.); K. Rahner, Karl Rahner im Gespräch mit Meinold Krauss, Stuttgart 1991, 30-35.

(37) Geist in Welt : Zur Metaphysik der endlichen Erkenntnis bei Thomas von Aquin, Innsbruck 1939. Esta y la segunda edición de 1957, a cargo de J. B. Metz, han sido recogidas en SW, Bd. 2: "Geist in Welt. Philosophische Schriften”, A. Raffelt (ed.), Düsseldorf-Freiburg i. Br. 1996. En adelante me referiré a esta obra simplemente como Geist in Welt.

(38) A. Raffelt, "Editionsbericht", en $S W$, Bd. 2, XXIII.

(39) Karl Rahner hizo como jesuita sus estudios de filosofía entre 1924 y 1927 en Feldkirch (Vorarlberg) y en el Bergmanskolleg de Pullach, cerca de München. Sus estudios de teología los realizó entre 1929 y 1933 en la casa de formación de los jesuitas alemanes en Valkenburg (Holanda), cerca de la frontera alemana. Para datos biográficos y antecedentes generales acerca de los inicios de Rahner en el ámbito de la filosofía, cf. la presentación de A. Raffelt - H. Verweyen, Karl Rahner, 13-53, esp. 13-28.

(40) "Espíritu se entiende como denominación de una capacidad de conocer lo metafísico remontándose más allá del mundo. Mundo es el nombre de la realidad que es accesible a la experiencia inmediata del ser humano. Cómo el conocimiento humano puede ser espíritu en el mundo: tal es la cuestión de la que se trata en este trabajo" (Geist in Welt, Innsbruck 1939, XIV. En adelante, seguiré citando según esta edición). Cf. K. Lehmann, "Philosophisches Denken im Werk Karl Rahners", 13.

(41) Para Rahner esta doctrina es en este contexto tan importante, que bien podría haber titulado su libro sencillamente así: "Conversio ad phantasma" (Geist in Welt, loc. cit.). La parte segunda de 
la cual se apoya a su vez en la noción de una "unidad originaria" de ser y conocer que se expresa en la índole permanente de tal movimiento del intelecto (42).

La intuición inicial es aquí la comprensión rahneriana -inspirada, como veremos, en Pierre Rousselot- del conocer no como encuentro o "choque" entre realidades distintas, sino como despliegue del ser. Ser y conocer se identifican, porque el ser es, de por sí, conocer (Erkennen) y ser conocido (Erkanntsein). Conocer es el "ser-cabesí" (Beisichsein) del ser (43), y este "ser-cabe-sí" es el ser del ente. Así, la mayor o menor "densidad de ser" (Seinsmächtigkeit) de un ente se determinará por su capacidad de "ser-cabe-sî", lo que según la interpretación de Rahner corresponde a aquello que Tomás designa como reditio in seipsum (44). Por todo ello, conocer es originariamente "subjetividad", antes que aquella "intencionalidad" propia de la relación de un cognoscente a un objeto distinto de él (45). Subjetividad, debido a la unidad originaria en que el conocer acontece; unidad originaria del ser "que hace brotar de sí al conocer y al ser conocido, precisamente como característica propia suya, fundando así la posibilidad intrínseca de una previa, esencial e inmanente relación recíproca de ambos. El ser mismo es la primigenia unidad 'unificante' del ser y del conocer en su 'realizada unidad' en el 'ser conocido' (...) Por tanto, lo conocido tiene que ser siempre, de alguna manera, el mismo ser del cognoscente" (46).

Esta unidad de ser y conocer que Tomás de Aquino ve realizada en Dios, Rahner la extiende analógicamente al conocer humano, en el que empero no se da de manera absoluta sino solo incoada, como una "anticipación" (Vorgriff) (47). Este concepto de anticipación adquirirá una especial importancia en su antropología trascendental, precisamente para expresar la idea de que el hombre, en cuanto "espíritu en el mundo", mediante su conocer aposteriorístico va realizando progresivamente, histórica y mundanamente, aquella unidad originaria de ser y conocer y va creciendo así en el grado de ser-cabe-sí mismo. Lo que libera a esta concepción de una posible sospecha de idealismo subjetivista, es precisamente la noción de que no se trata de una identidad entre sujeto y objeto del conocer ya actualmente plenificada, sino solamente anticipada. De modo que ha de entenderse que se trata de un proceso que parte de una unidad originaria (por lo que puede estar "anticipada"), pero que solo

Geist in Welt, que es la central y que abarca cuatro contundentes capítulos, lleva precisamente el título del libro, complementado por el subtítulo: "Die conversio ad phantasma".

(42) Para una presentación más detallada de este aspecto de la interpretación rahneriana de la metafísica del conocimiento de Tomás de Aquino, $c f$. las presentaciones de J. A. de la Pienda, Antropología trascendental de Karl Rahner. Una teoría del conocimiento, de la evolución y de la historia, Oviedo 1982, esp. 50-70; y de C. Schickendantz, Autotrascendencia radicalizada en extrema impotencia. La comprensión de la muerte en Karl Rahner, Anales de la Facultad de Teología, Vol. L, Santiago 1999, esp. cap. 20 59-93.

(43) V. gr. en Geist in Welt, 50. En esta misma página se utiliza la variante Beisichselbersein $(=$ sercabe-sí mismo). Sobre otras variantes de la expresión en diversos escritos de Rahner, cf. C. Schickendantz, o.c., 66, nota 39. En esta misma nota se señalan, además, numerosos otros lugares de Geist in Welt en que la expresión es usada.

(44) Geist in Welt, 161-168.

(45) J. A. De la Pienda, o.c., 53.

(46) C. Schickendantz, o.c., 67.

(47) Geist in Welt, 98-118, en que Rahner relaciona la expresión, que no está explícitamente en Tomás, con el concepto tomasiano de intellectus agens. Para una explicación complexiva de la noción rahneriana Vorgriff, cf. C. Schickendantz, o.c., 71-83. 
se realizará plenamente a través de un proceso histórico y mundano. Por lo demás, para Rahner es también importante aclarar que el concepto Vorgriff no debe entenderse como anticipación en sentido cronológico, sino como condición trascendental de posibilidad.

Como bien lo expresa Carlos Schickendantz, la intuición recogida aquí por Rahner de la doctrina tomasiana de la conversio ad phantasma es que dicha identidad originaria de ser y conocer se manifiesta concretamente en "la necesidad del espíritu humano de encarnarse en la materia para llegar a ser él mismo. La corporeidad es la manera necesaria y única por la que el hombre puede llegar a la realización de su ser espiritual (...) Para Rahner, en armonía con el idealismo alemán, el espíritu es un dato a priori del conocimiento humano, si bien necesitado de una articulación refleja e interpretativa y, desde él, y no a la inversa, se puede determinar metafísicamente lo que propiamente significan material y materia. Es este el camino de Geist in Welt" (48).

Lo anterior permite entender, a mi juicio, la razón filosófica de fondo por la que Rahner fundamenta su antropología trascendental en una metafísica del conocimiento. El acto de conocer es concebido como un acontecimiento "ontológico", más que como meramente "intencional", y se entiende que está posibilitado precisamente por aquella unidad originaria desde la cual el cognoscente ha de avanzar, desde lo ya anticipado, hacia una siempre mayor posesión del "ser-cabe-sí mismo" en la concreta inserción mundana del hombre. Así, de una metafísica del conocimiento se llega como de la mano y como consecuencia necesaria a una concepción antropológica en sentido estricto. El paso a una lectura teológica de esa antropología será, en definitiva, todo el conjunto de la obra de Karl Rahner a partir de su ensayo de filosofía de la religión El oyente de la palabra (Hörer des Wortes) (49).

\subsection{El influjo de Joseph Maréchal y su relectura trascendental-kantiana del punto de partida}

Como hemos dicho más arriba, la temática recién descrita es abordada por Rahner a la luz de la empresa filosófica del jesuita belga Joseph Maréchal, que consiste en una relectura trascendental kantiana de la metafísica del conocimiento de Tomás de Aquino, incluyendo empero a la vez un esfuerzo de superación de ciertos aspectos fundamentales del enfoque trascendental del mismo Kant. Podríamos decir, con Emerich Coreth, que lo que se da en la obra de Maréchal es un auténtico "giro trascendental de la metafísica escolástica (más exactamente, de la tomista)” (50).

Lo recién dicho vale sobre todo para el tomo $\mathrm{V}$ de El punto de partida de la metafísica, publicado en 1926 bajo el título: El tomismo ante la filosofía crítica (Le Thomisme devant la Philosophie critique) y que, como hemos dicho, el joven Rah-

(48) C. Schickendantz, o.c., 60.

(49) Hörer des Wortes. Zur Grundlegung einer Religionsphilosophie, München 1941; segunda edición reelaborada por J. B. Metz, 1963. Ambas ediciones han sido recogidas en SW, Bd. 4: "Hörer des Wortes. Schriften zur Religionsphilosophie und zur Grundlegung der Theologie”, A. Raffelt (ed.), Düsseldorf-Freiburg i.Br. 1997.

(50) E. Coreth, "Philosophische Grundlagen der Theologie Karl Rahners" (citado supra, nota 34), 527. 
ner estudió con especial interés y profundidad durante sus años de formación filosófica (1924-1927). En esta misma época y en la misma línea, aunque probablemente con menor intensidad, influyeron también fuertemente en él los escritos de Pierre Rousselot acerca del dinamismo inherente al conocimiento intelectual (51). Que la interpretación rahneriana de la metafísica del conocimiento de Tomás de Aquino se mueve en el espíritu inspirador de estos dos pensadores, es algo que el mismo Rahner reconocerá en el prólogo de la primera edición de Geist in Welt (52).

Los conocedores de Rahner coinciden en destacar que su enfoque trascendental tiene una innegable conexión con el pensamiento kantiano, pero ello muy fuertemente mediado por la relectura de Maréchal de dicha impronta trascendental. Rahner se beneficia, en la elaboración de su propia concepción antropológica, de la aproximación crítica y creativa del jesuita belga a Kant. Emerich Coreth (53) ha destacado el hecho de que hasta Maréchal, Kant había sido visto como un verdadero "aniquilador" de toda metafísica por el hecho de restringir el alcance del conocimiento a la experiencia y el fenómeno. Por otro lado, la pregunta trascendental kantiana por las condiciones de posibilidad del conocimiento se había tornado fundamental para las más nuevas empresas filosóficas, como el idealismo alemán, el neokantianismo y la filosofía existencial. Así, con su rechazo del pensar trascendental el pensamiento metafísico tradicional había llegado a plantearse como francamente opuesto a todas esas nuevas formas de la filosofía. Maréchal quiso, precisamente, superar esa contraposición tenaz asumiendo el pensar trascendental del gran filósofo moderno, pero bajo el ambicioso proyecto de "superar a Kant por medio de Kant" (54). Esto es: plantear la pregunta trascendental por las condiciones de posibilidad del conocimiento, pero con un alcance que trascendiera al mismo Kant, para mostrar así mediante el análisis trascendental no solo las condiciones apriorísticas en el sujeto finito limitado a la experiencia, sino además y sobre todo "la apertura apriorística del pensar al ser, en orientación (Hinordnung) dinámica al ser absoluto" (55).

Dicho de otro modo, Maréchal y, con él, Rahner asumen el enfoque trascendental kantiano, pero bajo la observación crítica de que el filósofo no habría considerado todas las condiciones de posibilidad del proceso del conocimiento al no tomar en cuenta el "rol de la finalidad dinámica en el proceso del conocimiento objetivo" (56). Este enfoque trascendental de la cuestión del conocimiento indica, en todo caso, cómo y en qué medida la temática antropológica, típica de la filosofía

(51) P. Rousselot, L'intelectualisme de saint Thomas, Paris 1902, segunda edición en 1924 (esto es, durante el período de estudios filosóficos de Karl Rahner).

(52) Geist in Welt, Innsbruck 1939, V. Cf. K. Lehmann, "Philosophisches Denken im Werk Karl Rahner", 13.

(53) E. Coreth, loc. cit

(54) “... el agnosticismo kantiano puede ser superado si se parte de sus propias premisas" (J. Maréchal, Le point de départ de la méthaphysik, Vol. V, citado en su versión alemana por $\mathrm{R}$. Schaeffler, "Christlicher Glaube und neuzeitliche Subjektivität - Karl Rahner" [ref. supra nota 19], 16, nota 7.)

(55) E. Coreth, loc. cit. Y concluye: "(Rahner) estaba convencido de que en una tal reflexión trascendental pueden mostrarse la apertura apriorística del espíritu humano al ser, la dimensión metafísica de la existencia (Dasein) humana y su orientación (Hinordnung) dinámica al ser absoluto de Dios" (ibid., 528).

(56) K. Lehmann, "Philosophisches Denken...", 17-18. 
moderna, comienza a ser integrada en la tradición de pensamiento más fuertemente asentada en los círculos católicos.

\subsection{Rahner y Heidegger: el horizonte ontológico-existencial}

Por último, tal empeño se abre a las grandes intuiciones de la corriente de pensamiento más importante de la primera parte del siglo $\mathrm{XX}-\mathrm{y}$ acaso de todo ese siglo-, representado por la filosofía existencial y su principal exponente, Martin Heidegger (57). Ya hemos mencionado el fuerte influjo que él tuvo en Rahner -pero también en otros importantes pensadores cristianos contemporáneos a él-durante el período de estudios en vistas a un finalmente fallido doctorado en filosofía en Freiburg (1934-1936) (58). Y aun cuando no parece ser exacto considerar a Rahner como un "discípulo" en sentido estricto del gran filósofo, incluso durante aquellos años, el mismo jesuita alemán manifestó en más de una ocasión, sobre todo al final de sus días, su admiración y reverencia hacia Heidegger (59).

La razón por la cual no ha de considerarse a Rahner como un discípulo de Heidegger en el sentido estricto de la expresión, es doble: en primer lugar, porque, como el mismo jesuita lo precisó en su momento, no es posible hablar de una dependencia de contenido, pues se trata de la relación de un teólogo con un filósofo. Es más, Rahner destaca el hecho de que ni uno solo de los contenidos de su pensamiento teológico podría ser hallado en el discurso filosófico de Heidegger; de modo que si hay que reconocer una cierta dependencia suya con respecto al filósofo, esta debe buscarse sobre todo en los aspectos formales del pensamiento, la estructura del discurso racional, la forma de interpretar un texto, la concepción del pensar como pregunta y como búsqueda. He ahí la gran influencia (60). En segundo lugar, después de aquella cercanía del tiempo de Freiburg, Rahner no siguió el ulterior desarrollo del pensamiento de Heidegger. Esto pudo deberse a diversos factores relacionados con la evolución experimentada por cada cual en su propio camino; pero el hecho es que Rahner reconoció al final de su vida no haber continuado la lectura atenta de los posteriores textos heideggerianos (61).

(57) Cf. O. Muck, "Heidegger und Karl Rahner", Zeitschrift für Katholische Theologie 116 (1994) 257-269; E. Brito, "La réception de la pensée de Heidegger dans la théologie catholique", Nouvelle Revue Théologique 119 (1997) 352-374; M. Berciano, "Influjos de la filosofía de Heidegger en al teología reciente: R. Bultmann, P. Tillich, K. Rahner", Burgense. Collectanea scientifica 17 (1976) 445-473.

(58) Coincidieron con Rahner en este período, además de su compañero jesuita J. Lotz, M. Müller, G. Siewerth y B. Welte. A este grupo se le ha llamado "escuela católica de Heidegger" (katholische Heidegger-Schule), pero últimamente se ha relativizado el grado de contacto o de adhesión de Rahner a ellos como colectivo (cf. K. Lehmann, "Philosophisches Denken...", 15 s; E. Coreth, o.c., 528 s).

(59) ¿Qué ha de decir un discípulo [Schuler] de Martín Heidegger que es teólogo, que es teólogo hasta tal punto que no tiene la pretensión de ser filósofo, para el $80^{\circ}$ cumpleaños de aquel al que, aun siendo teólogo, venera como a su maestro? (...) ¿Ha de confesar con toda sencillez y llaneza que ha tenido muchos buenos maestros de la palabra hablada, pero que sin embargo solo ha tenido uno al que puede venerar como su maestro, precisamente a Martín Heidegger?" (en: R. Wiser [Ed.], Martín Heidegger im Gespräch, Freiburg-München 1970, 48. Tomo la traducción de la cita de M. Berciano, "Influjos de la filosofía de Heidegger...", 463, incorporando leves correcciones.

(60) P. Imhof / H. Biallowons (Ed.), Glaube in winterlicher Zeit. Gespräche mit Karl Rahner aus den letzten Lebensjahren, Düsseldorf 1986, 28.

(61) Cf. K. Lehmann, "Philosophisches Denken...", 20. 
En el enfoque de fondo del pensamiento rahneriano, el gran influjo del Heidegger de Sein und Zeit parece ser la ampliación de horizontes que le abre el análisis existencial del Dasein. Esto le permite apuntar su perspectiva trascendental, incluso en su aspecto explícito, más allá del mero conocimiento, como algo que efectivamente abarca todo el conjunto de las aspiraciones más profundas, el querer y el actuar del hombre. En este sentido, el pensamiento heideggeriano presta una decisiva base ontológica al reenfoque antropológico de la teología emprendido por Rahner, lo que se expresará concretamente en ciertos conceptos fundamentales asumidos y desarrollados por este. Entre ellos destacan la noción de "existencial" como determinación ontológica de la existencia humana y que más tarde se concretará en la noción teológica-antropológica de "existencial sobrenatural" (übernatürliches Existential) y, sobre todo, la fuerte consideración de la historicidad (Geschichtlichkeit) esencial del existir humano (Dasein), que servirá a Rahner para expresar y desarrollar sistemáticamente el contenido bíblico de la historia como "lugar posible" de la revelación divina. La noción de que la historia (Geschichte) puede ser $-\mathrm{y}$ de hecho ha sido- "historia de salvación" (Heilsgeschichte), ha sido una temática especialmente cara a Rahner para expresar su comprensión trascendental de la revelación salvífica. Su intuición de fondo es que si bien ambos conceptos no se identifican -por cuanto la historia de la salvación no "es", sin más, la historia en cuanto tal, sino que más bien "acontece en" ella-, la concreta historicidad de la salvación es de por sí testimonio elocuente de la dimensión trascendental del actuar salvífico de Dios en favor del hombre (62).

\subsection{Visión de conjunto}

Emerich Coreth ha destacado el hecho de que Rahner mantuvo siempre una misma posición filosófica fundamental, a saber, la comprensión trascendental-metafísica del espíritu humano en apertura y referencia al ser absoluto; en definitiva, "en apertura al misterio infinito de Dios" (63). Por lo mismo, es importante hacer presente el sentido rahneriano preciso del adjetivo trascendental: "como una categoría tomada de la filosofía moderna pero reinterpretada creativamente en función de una concepción teológica del hombre no opuesta ni simplemente yuxtapuesta a aquella, sino articulada en un diálogo fecundo" (64). Es opinión unánime entre los conocedores de Rahner el que todas y cada una de las nociones filosóficas que él asumió deben ser entendidas en un sentido muy específico y riguroso dentro de su pensamiento creativo y propiamente teológico. Pero siendo ello innegable, no ha de entenderse como expresión de una disciplina cerrada o autorreferente, sino, muy por el contrario, como signo de una teología que busca articularse, en su especificidad, desde una actitud básica de apertura a los impulsos y palpitaciones de la situación histórica y cultural en la que está inserta en cada momento de su quehacer.

(62) A este aspecto me he referido, con las correspondientes referencias a textos de Rahner y a la literatura secundaria, en mi ya citado artículo "Teología trascendental y praxis", esp. 482-485.

(63) E. Coreth, "Philosophische Grundlagen...", 531.

(64) F. Berríos, "Teología trascendental y praxis...", 471. 
Un importante escrito de Rahner sobre el método en la teología, al que ya hemos aludido en el presente trabajo, incluye una observación que invita a situar el enfoque trascendental en un horizonte más amplio: "la teología trascendental no es el todo de la teología y no puede tener la pretensión de ser más que un título o un aspecto" (65). Y aunque es conocida y suficientemente reconocida la centralidad de este "aspecto" en la teología de Rahner, no es menos elocuente que él mismo en estas importantes reflexiones sobre su método concluya con una invitación a la reductio in mysterium (66). Es también de destacar el hecho de que en este escrito considerado "tardío" (67), el autor retome como un corolario de sus reflexiones una de sus intuiciones teológicas primigenias, a saber, que hay una afinidad radical entre la teología y la mística, que expresa un sentido profundo del misterio absoluto de Dios (68). Precisamente, la perspectiva trascendental contribuye a la comprensión de Dios como Alguien que no puede ser considerado por el hombre como un "objeto más" del conocimiento finito, sino, al contrario, como la "fuente de la subjetividad" -que a su vez se articula como apertura- y, a la vez, como su sentido último (69).

Al comienzo de estas páginas destacábamos la apreciación de Rahner de que el giro antropológico de la teología es posible y necesario por el hecho básico de que no hay, para el cristianismo, una real contradicción Anthropozentrik-Theozentrik. Esta afirmación supone una concepción de la inmanencia, de la trascendencia y de la relación entre ambas, que la justifique y sostenga. Desde la sólida base filosófica que aquí hemos descrito someramente (70), toda la teología trascendental del jesuita alemán, en especial su teología de la gracia, será, en definitiva, un gran desarrollo de aquella convicción fundamental.

(65) “Überlegungen” (ref. en la nota 19), 95. Y más adelante: "La teología trascendental no puede y no quiere ser la teología [destacado del original], sino un momento en ella, porque la teología (o mejor y más exactamente: la fe, cuyos momentos de reflexión y cuya irreductibilidad a la reflexión [Unreflektierbarkeit] la teología reflexiona) debe decir siempre lo históricamente concreto en su indeductibilidad [Unableitbarkeit] y, con ello, hacer comprensible, precisamente, que esto concreto [dieses Konkrete] de la historia puede concernir realmente a los hombres en su existencia y subjetividad" (p. 112).

(66) Tal es el contenido de la última de las tres "lecciones" (Vorlesungen) que componen el citado escrito: pp. 113-126. Cf. Y. Tourenne, "Articulation de la philosophie chez le dernier Rahner (1969-1984)", citado supr. en la nota 19.

(67) Tiene su origen en una exposición preparada por Rahner para un simposio teológico realizado en Montreal en el verano de 1969 ("Überlegungen", 79, nota 1).

(68) Esta intuición está ya formulada en su tesis de doctorado en teología, presentada en 1936: $E$ latere Christi : Der Ursprung der Kirche als zweiter Eva aus der Seite Christi des zweiten Adam. Eine Untersuchung über den typologischen Sinn von Joh 19,34. - original mecanografiado inédito, Karl Rahner-Archiv, Innsbruck: I B 6, recogida en $S W$, Bd. 3: "Spiritualität und Theologie der Kirchenväter”, A. R. Batlogg/E.Farrugia/K.-H. Neufeld (eds.), Freiburg i.B. 1999.

(69) Sobre este aspecto, cf. R. Schaeffler, "Christlicher Glaube", 16 s.

(70) Sobre la relación entre filosofía y quehacer teológico en el pensamiento de Rahner, cf. etiam sus escritos: "Philosophie und Theologie", STh VI, 91-103 y "Philosophie und philosophieren in der Theologie", STh VIII, 66-87. 


\section{ANTROPOLOGÍA TRASCENDENTAL Y PRAXIS: LOS CAMINOS DE BLONDEL Y RAHNER}

A luz de todo lo anterior resulta especialmente interesante profundizar en la opción de Rahner de tomar como punto de partida de su antropología trascendental el camino de una metafísica del conocimiento (Espíritu en el mundo), luego complementado con el de una filosofía de la religión (El oyente de la palabra), a diferencia de la vía seguida por el célebre filósofo francés Maurice Blondel, tan influyente en la Nouvelle théologie -que el jesuita conoció bien (71)- y en el enfoque que los grandes representantes de la misma dan a la cuestión de la relación naturaleza-gracia (72). Blondel, también representante eminente del método trascendental, había optado por una "ontología de la acción”, en un enfoque de gran interés para el tema que aquí nos ocupa.

\subsection{El enfoque de Blondel}

Lo dicho podrá comprenderse mejor con una somera presentación del enfoque trascendental blondeliano en L'Action. El hombre actual, aunque esté privado de la gracia, se encuentra interiormente ordenado a la visión beatífica. Hay en él una ordenación interior permanente al fin último sobrenatural. Por el acento en esta intuición central, a Blondel se le acusó de inmanentismo, del mismo inmanentismo del que más tarde se acusaría a $\mathrm{H}$. de Lubac (73). Por eso, aunque piensa que el estado de "naturaleza pura" no existe ni ha existido nunca de hecho y que por lo tanto no es posible definir su estructura y sus condiciones reales de existencia (74), en L'action de 1936 reconoce y justifica su posibilidad:

“HHay que decir (...) que un estado de naturaleza pura es imposible, a no ser que esté dolorosamente frustrado y que los seres espirituales no contienen ninguna perfección (achèvement) relativa a su condición y capaz de procurar la alegría de un deber cumplido, de un servicio dado, de una humilde y meritoria virtud recompensada? De ninguna manera: pues precisamente porque la inteligencia de los espíritus imperfectos conoce sus límites y juzgaría insensata (déraisonnable) esta presunción de la cual se escandalizan los antiguos sabios, la actitud normal sería para ellos una reserva sumisa ante la sublimidad divina, un rol de alabanzas modestamente adoratrices unido al ejercicio de virtudes naturales bajo la conducción de la ciencia, de la razón, de la mutua amistad,

(71) Cf. v. gr. las alusiones de Rahner a dicha escuela en "Über das Verhältnis von Natur und Gnade", STh I, 323-345, 324. La versión original de este escrito, según lo indica la nota 1) de la señalada edición de los Schriften zur Theologie, se encuentra en Orientierung 14 (1950) 141-145.

(72) Cf. J. A. de la Pienda, El sobrenatural de los cristianos, Salamanca 1985; N. Knoepffler, "Blondels Action von 1893 und Rahners transzendentaler Ansatz im Grundkurs - eine unterirdische Wirkungsgeschichte", Theologie und Philosophie 1 (1997) 91-96. Cf. H. Verweyen, Gottes letztes Wort. Grundri der Fundamentaltheologie, Düsseldorf 1991, 153-156.

(73) De la Pienda, El sobrenatural..., 23.

(74) “... como lo intentaban los escolásticos y también Malévez, con el método de análisis trascendental" (ibid., 25). 
conforme a la unidad de naturaleza y a la sociedad de los espíritus. Sería pues falso decir que un estado de naturaleza pura razonable es inconcebible, falso igualmente pretender que fuera de la fe positiva una moral natural y de justas sanciones no tendría consistencia alguna ni justificación posible” (75).

En atención a esto, podría considerarse que Blondel se ubica -junto a Rahner, Bribois y Malévez- en una posición intermedia entre la teoría neoescolástica extrinsecista del sobrenatural y la línea más radical del H. de Lubac de Surnaturel.

En cuanto al método, que es el aspecto que aquí más nos interesa, Blondel hace un análisis fenomenológico cuyo punto de partida es la naturaleza concreta e histórica del hombre. Su aproximación es un análisis del deseo humano más profundo, tal como se revela en la acción del hombre. Descubre así en su sicología un deseo del bien último trascendental, lo "único necesario". Así considerada en su concreción e historicidad, la naturaleza humana manifiesta una fundamental e inalienable necesidad de actuar, que a su vez expresa o traduce su dinamismo interno. Con el análisis del "movimiento dialéctico implicado en la acción" (76), Blondel busca develar el verdadero sentido y orientación de la tendencia volitiva necesaria (vouloir nécessaire) que acompaña a todas las acciones del hombre, reconózcalo este o no (77), pero sin dejar de subrayar, por otra parte, "el carácter libre de la opción necesaria".

Blondel lo expresa claramente, en una síntesis apretada:

"la necesidad, para el hombre, de optar, no hace más que manifestar su voluntad de ser lo que quiere. Su acción tiene, pues, un ser necesario. Pero este ser, si el hombre pretende encontrarlo o verlo completamente en sí mismo, se vuelve contra él. Si su libertad, frente a la alternativa que se le impone, no lo encamina hacia una forma nueva de la vida, es su perdición. Inútil conocer ya esta vida superior, para saber que, si sus actos no la tienen en cuenta (repoussent) falta su destino. No ser cambiado en absoluto es, para el hombre, la muerte de la acción. Solo podrá vivir, pues, renaciendo, por así decirlo, en el esfuerzo de un nuevo alumbramiento (enfantement) y abriéndose a otra acción distinta de la suya. Pero, sea cual sea la manera en que se resuelva el conflicto, la opción de la libertad no suprimirá lo que haya de ser necesario en la acción querida (action voulue)" (78).

Con todo esto, De la Pienda considera que varios de los aspectos fundamentales de la noción rahneriana de existencial sobrenatural (79) "ya fueron intuidos por Blondel en su análisis fenomenológico de la acción humana" (80). Pero este autor se

(75) M. Blondel, L'Action I, Paris 1936, 417, citado en ibid., 24. La citas textuales que aquí se hacen de los textos de Blondel, son traducciones mías.

(76) Tomo esta expresión de De la Pienda, o.c.

(77) Cf. M. Blondel, L'Action. Essai d'une critique de la vie et d'une science de la pratique, Paris 1893, 339 ss (en la cuarta parte de la obra: "L'être nécessaire de l'action").

(78) M. Blondel, L'Action, 1893, 356.

(79) En realidad, este autor traduce la expresión "übernatürliches Existential” como "existenciario sobrenatural”, al parecer siguiendo la traducción de J. Gaos de Sein und Zeit de Heidegger.

(80) De la Pienda, El sobrenatural, 25, con la enumeración de tales aspectos. 
limita a destacar que en Blondel hay antecedentes importantes de la antropología trascendental de Rahner. Otra cosa distinta, que sí intenta Nikolaus Knoepffler (81), es tratar de delimitar en qué medida y de qué modo ha podido haber una concreta influencia de Blondel sobre Rahner en este punto decisivo.

\subsection{Blondel y Rahner}

No deja de sorprender el hecho que el tema de una eventual influencia de Blondel sobre Rahner suele ser omitido en los estudios sobre el trasfondo filosófico del método trascendental de este último, o bien es considerado como un influjo menor (Lehmann) (82), "indirecto" (Raffelt-Verweyen) o "subterráneo" (Knoepffler). La pregunta de fondo que aquí podría plantearse es si esta manera diversa de desarrollar el enfoque trascendental pudiera implicar, por parte de Rahner, una cierta infravaloración de la dimensión práctica del despliegue histórico de la existencia humana en apertura al Infinito.

En otro lugar he mostrado que la temática de la praxis es un tópico transversal en la obra teológica de Rahner, si bien en muchos momentos no constituye un objeto directo o explícito de su atención (83). Su enfoque trascendental de la teología, en especial de la doctrina de la gracia y de la cristología, otorga un lugar central a la libertad humana interpelada desde dentro por Dios en el transcurso de la historia. Con ello, la praxis histórica, entendida como la actualización de la libertad humana creada, trascendentalmente sostenida y a la vez realmente interpelada, deviene un aspecto de primerísima importancia. Pero, como hemos visto, el punto de partida rahneriano no es este, sino una metafísica del conocimiento. Intentemos una mejor comprensión de esta opción.

Por de pronto, es necesario precisar qué tipo de contacto tuvo Karl Rahner con el pensamiento trascendental blondeliano (84). Por referencias explícitas del jesuita (85), sabemos que él conoció y valoró en gran medida el pensamiento de Blondel; pero se ha podido establecer que no leyó L'Action ni la "Carta" de 1896 en que el autor francés expone la concepción metodológica de su filosofía de la religión en diálogo con la apologética contemporánea. En cambio, sí formaron parte de la lista de lecturas de Rahner en 1932/33 (86) los textos blondelianos Le probléme de la philosophie catholique (1932) (en la que empero son recogidas ciertas partes de dicha Carta) y su Itinéraire philosophique (1928). Es decir, Rahner se habría familiarizado, mediante sus lecturas, más bien con la concepción filosófica del Blondel tardío, nuevamente aproximado al "pensamiento metafísico y escolástico" (87).

Debido a ello hoy tiende a destacarse, como hemos advertido, el carácter más bien indirecto o "subterráneo" de la influencia del enfoque trascendental blondelia-

(81) En el ya citado artículo "Blondels Action von 1893 und Rahners transzendentaler Ansatz im Grundkurs...".

(82) V. gr. K. Lehmann, "Karl Rahner. Ein Porträt", 31*.

(83) Cf. F. Berríos, "Teología trascendental y praxis...", acápites 2 al 5, págs. 477-496.

(84) Cf. A. Raffelt - H. Verweyen, Karl Rahner, 17-21, esp. 19 s.

(85) V. gr. la laudatoria alusión en "Theologie und Anthropologie", 56, citada más arriba.

(86) Disponible en el Archivo Rahner: KRA IV A 150, citado por Raffelt-Verweyen, Karl Rahner, 20.

(87) Loc. cit. 
no sobre Rahner. N. Knoepffler sostiene la tesis de que el enfoque trascendental rahneriano, y específicamente como se expresa en su obra de madurez Grundkurs des Glaubens, depende "subterráneamente" de la perspectiva trascendental de L'Action de M. Blondel, aunque también hay, a su parecer, "diferencias esenciales" entre ambos autores. En su esfuerzo por tomar nociones fundamentales de la filosofía kantiana, pero a la vez superándola (con el análisis del carácter dinámico del conocimiento humano), Rahner se ubica en una tradición que viene de Blondel y que llega a él, reiterémoslo, por la mediación de Pierre Rousselot y, sobre todo, de Joseph Maréchal.

En una perspectiva aun más amplia, Raffelt y Verweyen, por su parte, reconocen un influjo blondeliano "indirecto" sobre Rahner a través del contacto que tuvieron con Blondel los ya mencionados pero también otros importantes intelectuales jesuitas franceses de la primera mitad del sigo XX, cuya influencia es, a su vez, inobviable para una cabal comprensión del pensamiento de Rahner. La interpretación rousselotiana de Tomás de Aquino, de tanta importancia para Rahner, "le debe mucho al análisis de la dinámica subjetiva en L'Action" (88), pero también Teilhard de Chardin, Henri de Lubac y toda la Nouvelle théologie francesa de los años cuarenta, muy valorada en el ambiente teológico alemán, fueron fuertemente influidos por Blondel.

Y hay otros puntos de contacto particulares. Por de pronto, la ya aludida asunción crítica del kantismo. En Blondel el esfuerzo por dialogar con Kant y a la vez superar su enfoque, se expresa elocuentemente en el subtítulo de L'action: "Ensayo de una crítica de la vida y de una ciencia de la práctica". Concentra su atención en aquello que se manifiesta como "necesario" en todo querer y obrar humano. Su método en L'action es la "crítica inmanente", que se basa en la idea de que "en toda situación de la naturaleza y del espíritu está presente lo Infinito" (89). La acción muestra que todo querer, todo deseo que se dirige a lo finito, experimenta la contradicción. Porque a todo deseo subyace el anhelo de lo infinito. Y este "querer fundamental" (= volonté voulant) no es solamente fundamento trascendental de posibilitación del querer, sino un acto volitivo real, aunque desde el punto de vista introspectivo-sicológico no puede ser directamente concebido, sino siempre a partir del concreto hacer o actuar deseado (volonté voulue) (90).

Otro aspecto de la influencia de Blondel sobre Rahner que Knoepffler destaca: para Blondel el cumplimiento del deseo, así como el desear mismo, el anhelo, solo son posibles en el hombre como don de Dios. Blondel llama "sobrenatural" precisamente a este "don divino plenificador". La determinación rahneriana de la "experiencia trascendental" como "sobrenatural" (gratuita, divina, aunque "existencial") encuentra aquí sus raíces a través de la mediación específica de teólogos franceses como Rondet, Bouillard y de Lubac (91).

(88) Loc. cit.

(89) M. Blondel, "Une des sources de la pensée moderne: L'évolution du Spinozisme “(1984), en H. Gouhier (Ed.), Dialogues avec les philosophes: Descartes, Spinoza, Malebranche, Pascal, saint Augustin, Paris 1966, 33, citado por N. Knoepffler, o.c., 93, nota 11.

(90) P. Henrici, "Maurice Blondel und die 'Philosophie der Action', en E. Coreth - W. M. Neidl - G. Pligersdorfer (Ed.), Christliche Philosophie im katholischen Denken des 19. und 20. Jahrhunderts 1: Neue Ansätze im 19. Jahrhundert, Graz 1987, 543-584. 552, citado por ibid., 93.

(91) Ibid., 93. 
Por último, otra influencia: la idea rahneriana del Logos encarnado como causa final y símbolo absoluto de Dios (92) está presente en la idea blondeliana del Panchristismus: Jesucristo es el único sujeto absoluto, que "a través de la unidad de su ser y padecer funda absolutamente la pasividad y actividad de los fenómenos" (93). Dios realiza en la creación su hacer absoluto; y asimismo realiza Él en la encarnación, y sobre todo en el clímax de la Pasión, el padecer absoluto.

Tanto De la Pienda como Knoepffler se ocupan, sin embargo, en destacar las diferencias entre Blondel y Rahner. Como hemos dicho al comienzo, para el tema de la presente investigación es altamente interesante determinar estas relaciones y tratar de dilucidar por qué Rahner, que conoció bien la Nouvelle théologie -esta sí claramente influida por Blondel-, no siguió en su antropología la línea blondeliana de una "ontología de la acción", sino la línea más especulativa del análisis trascendental de una metafísica del conocimiento, en la senda de Joseph Maréchal.

Para De la Pienda, la principal diferencia entre Blondel y Rahner radica en que el primero no recurre explícitamente en L'action a la noción de desiderium naturale videndi Deum, a pesar -es necesario acotarlo- de la importancia que le concede al tema del deseo manifestado en la acción humana. Ello se debe a que para Blondel lo que pone en juego la dialéctica de la acción no es propiamente el fin último (la visión beatífica) sino el desafío presente implicado en el llamado (gratuito) de Dios a vivir en comunión con Él cumpliendo su voluntad. En el deseo de lo sobrenatural iría implícita, según esto, más bien una ascética concreta.

Nikolaus Knoepffler destaca, por su parte, la diferencia de los puntos de partida. Blondel parte del hecho del actuar. Rahner asume la perspectiva de una teoría del conocimiento. Más bien dicho: de una "metafísica del conocimiento" a partir del principio escolástico de la identidad de ser y conocer. En uno el punto de partida es el "dinamismo del querer, del desiderium"; en el otro se trata de un "dinamismo del conocer".

Un aspecto fundamental que sería necesario precisar es que, probablemente, Rahner, con su análisis trascendental, busca las condiciones de posibilidad del conocimiento y en definitiva del conocimiento absoluto, de la absoluta apertura al ser. Pero luego del planteamiento inicial ya no continúa, a diferencia de Blondel, con una argumentación filosófica (94). Este aspecto decisivo habría que profundizarlo tomando en consideración también aspectos biográficos de Karl Rahner, en el sentido de la evolución que tuvo en su vida la relación de su pensamiento teológico con la filosofía. Este parece haber sido un aspecto importante de la trayectoria intelectual del jesuita alemán, quien, pese a las reiteradas instancias de algunos de sus discípulos frente a ciertas críticas filosóficas a Hörer des Wortes, nunca emprendió la tarea de una tal "relectura" de las problemáticas fundamentales abordadas por su obra (95).

(92) K. Rahner, "Zur Theologie des Symbols", STh IV, 293s, citado en ibid., 94, nota 17.

(93) P. Henrici, "Maurice Blondel...", 565, citado en loc. cit.

(94) Cf. H. Verweyen, Gottes letztes Wort, 164-169.

(95) Cf. K. Lehmann, "Philosophisches Denken im Werk Karl Rahners", 22-27, con especial referencia a las críticas formuladas por E. Simons, Philosophie der Offenbarung in Auseinandersetzung mit "Hörer des Wortes" von Karl Rahner, Stuttgart 1966 y A. Gerken, Offenbarung und Transzendenzerfahrung. Kritische Thesen zu einer zukünftigen dialogischen Theologie, Düsseldorf 1969. 
Volviendo a lo central, en estricto rigor Rahner con su teorema del existencial sobrenatural va a desarrollar una antropología teológica: una comprensión del hombre como acontecimiento (Ereignis) de la autocomunicación trascendental de Dios (96). Con ello, la "revelación trascendental" aparece como siempre, de hecho, dada. Con el acontecimiento de Cristo ella adquiere su forma absoluta; por eso Cristo es su "causa final" y su "confirmación". Blondel, en cambio, se limita a mostrar que en el querer humano se manifiesta un anhelo por lo infinito, cuya satisfacción se da solo como un gratuito acontecimiento histórico. Por eso el acontecimiento de Cristo no puede ser "causa final" de una siempre dada revelación trascendental, sino que solo funda el vinculum substantiale. Este aspecto también merecería ser retomado en profundidad.

Por último, otra diferencia, también observada por Knoepffler y que me parece de gran interés, está dada por el objetivo de cada obra expresado en sus respectivos subtítulos: Rahner agrega al título del Curso fundamental sobre la fe, la especificación: introducción al concepto del cristianismo. Se trata, pues, de una aproximación racional, especulativa, un esfuerzo por dar razón de lo creído. Blondel intenta, en cambio, con L'Action una "crítica de la vida" y, con esa misma intencionalidad, "de una ciencia de la práctica". Su análisis de la acción humana parecería apuntar así más bien a animar, al menos más directamente, a una decisión por una "praxis de fe católica". Es necesario evitar, con todo, una lectura superficial de esta diferencia, so pena de caer en el simplismo. De maneras diversas o desde distintos puntos de partida teóricos, hay una identidad de fondo en cuanto al camino elegido, el método trascendental, que no es sino la expresión de una convicción profunda que está ligada, a su vez, a una crítica radical del "extrinsecismo" craso de la concepción neoescolástica de la relación inmanencia-trascendencia. La autodonación de Dios, con sus efectos en el hombre y en su inserción en el mundo, pasa a ser comprendida, en sintonía con la doctrina tradicional de la fe y a la vez con la sensibilidad moderna, como un acontecer en el hombre históricamente situado. Esta intuición fundamental será probablemente la de mayor repercusión en la concepción de Dios, de la realidad humana y de su relación en la teología a partir del siglo XX.

Podemos concluir, pues, que el enfoque trascendental de Rahner basado en una metafísica del conocimiento no comporta una relativización o desvalorización del despliegue práxico del hombre en la historia, puesto que ello constituiría una contradicción interna de su propia perspectiva trascendental, y que más bien se explica por la tradición escolástica en que está enraizada su formación filosófica y teológica y sobre todo por la influencia, a fin de cuentas sin contrapeso, de Joseph Maréchal con su lectura kantiana, a la vez creativa y crítica, de las intuiciones de Tomás de Aquino.

(96) Del hombre como "conformado por Dios como causa cuasiformal" (von Gott quaziformalursächlich überformte). 


\section{RECAPITULACIÓN Y PERSPECTIVAS}

El interés último de estas reflexiones ha sido vislumbrar el significado de la antropología trascendental de Karl Rahner para una comprensión teológica de la praxis histórica en apertura a la modernidad. Precisamente por ello hemos partido por una explicación del "recentramiento antropológico" de la teología como programa fundamental de la obra del jesuita alemán (acápite 1.). Tal recentramiento, como él mismo lo ha dicho, tiene como una de sus justificaciones principales el carácter insoslayable, para la teología, del giro antropocéntrico que la filosofía occidental experimentó en la cultura moderna en la tradición que arranca de Descartes y que Rahner considera hasta la filosofía existencial y la ontología fundamental de $\mathrm{M}$. Heidegger.

En apertura a esa corriente, pero a la vez recuperando muy profundamente la tradición escolástica de Tomás de Aquino, el pensamiento de Rahner se encamina a dicho recentramiento antropológico desde una perspectiva trascendental, que va a determinar el método de su quehacer teológico. A la presentación general y al análisis de algunos aspectos centrales de tal proceder metodológico se ha dedicado el segundo acápite el presente trabajo.

Es necesario precisar el sentido y el alcance de tal método y sus consecuencias para una lectura teológica de la praxis histórica. Tal ha sido el interés de fondo del presente estudio. En función de ello, en el tercer acápite se ha hecho una presentación de las principales líneas que concurren en la formación del sustrato filosófico de la impronta antropológico-trascendental de la teología del jesuita alemán. La praxis como tema de reflexión debía ser ubicada en el contexto general de la antropología que decanta, en el pensamiento de Rahner, de todo ese proceso.

Hemos concluido con una breve comparación entre el método trascendental que adquiere diferentes formas en Rahner y en el influyente filósofo cristiano Maurice Blondel (acápite 4.). Ambos, por caminos distintos, desembocan en una antropología determinada por el sobrenatural como momento interno. A partir de la constatación de que el teólogo alemán ha optado por el camino de una metafísica del conocimiento para llegar a una tal antropología trascendental, mientras que Blondel parte de una "ontología de la acción", se hace necesario, primero, precisar esta percepción de la diferencia y luego, logrado ello, profundizar en la comprensión de las intuiciones de fondo que guían cada opción y de su posible repercusión para una reflexión teológica sobre la praxis hoy. Igualmente interesante es la consideración de los aspectos que comparten ambas formas de reflexión trascendental. Todo ello constituye, en rigor, una tarea que supera las posibilidades de este trabajo, pero que ha quedado al menos bosquejada en sus principales contornos.

Un resultado relevante de todo este recorrido ha sido constatar la necesidad de distinguir-sin separar en la obra teológica de Rahner entre los antecedentes concretos y el específico punto de partida de la antropología transcendental, por una parte, y el desarrollo global de la misma en el conjunto de esa obra, por otra. No se postula con esto una relativización de tales antecedentes ni una mirada de su obra que disocie artificialmente una consideración diacrónica de otra sincrónica. Pero, a mi juicio, solo la complementación de ambas aproximaciones permitirá entender el modo como se relacionan en la teología del jesuita aspectos diversos, incluso apa- 
rentemente contradictorios o alternativos. Esta es tal vez la mayor fortaleza del pensamiento rahneriano y a la vez uno de sus aspectos más cuestionados en cuanto a la concreta manera de llevarla a cabo: la integración de lo diverso en una visión unitaria de la realidad histórica, del hombre y del actuar mismo de Dios en ellos.

En tal sentido hemos hecho más arriba una alusión a la "recuperación" que hace Rahner, en el contexto de una reflexión "tardía" sobre el método en teología, de una intuición primigenia de su pensamiento: el vínculo estrecho entre mística y teología, como signo de que el método trascendental, lejos de debilitar el sentido del misterio absoluto que es Dios, se orienta a radicalizar la comprensión de ese misterio como fuente y sentido último de la subjetividad integralmente considerada, "en conocimiento y libertad" (97). Se trata aquí de la integración de trascendencia e inmanencia, de misterio absoluto y finitud, de soberanía divina y libertad personal-humana, de trascendentalidad e historicidad. Integración radical en un sentido sincrónico.

Pero, además, salta a la vista que en Rahner esa idea de "recuperación" hay que entenderla más bien como la capacidad de retener y desarrollar en el tiempo ciertas intuiciones fundamentales, enriquecidas y potenciadas con el aporte de otros enfoques y otras intuiciones descubiertas o adquiridas en ese mismo transcurso, como una suerte de testimonio concreto de la historicidad de la teología y -en contra de la opinión de algunos detractores del jesuita- de la misma impronta trascendental de su pensamiento teológico (98). Se trata aquí de la dimensión diacrónica de la búsqueda de integración.

A ambas aproximaciones, claramente permeadas por la sensibilidad moderna, es esencial el rasgo de la historicidad. Historicidad de la salvación como don y como acontecimiento de encuentro. La integración de lo diverso en la unidad acontece siempre históricamente. Y en cuanto tal acontecer, la noción de "antropología trascendental" y el método teológico a ella asociada implican, necesariamente, todo cuanto el ser humano despliega en su existencia ante la invitación del Dios que lo interpela, al decir de Rahner, trascendental y categorialmente. Una reflexión teológica trascendental sobre la praxis histórica -en el sentido amplio en que la comprendemos en el presente trabajo- debería, pues, ubicarse en tal horizonte: no solo como una cuestión abordable desde la pregunta ética -por cierto, legítima y necesaria-, sino ante todo como ocasión para pensar y valorar la posibilidad para el ser humano - para todo cuanto él es, hace y busca- del encuentro integrador salvífico con Dios, en su dimensión tanto sincrónica como diacrónica.

Aquí destaca la importancia central de la fuente espiritual ignaciana de la teología de Karl Rahner y de su método antropológico-trascendental como "racionalidad cimentada preconceptualmente" en la fe en un Dios que "se hace experimentable en forma no-objetual (ungegenständlich) a través de decisiones humanas, para

(97) Grundkurs des Glaubens (ref. supra nota 18), 149.

(98) Acerca de la importancia metodológica de considerar en la investigación sobre Rahner el contexto (histórico y social-sociológico) de la génesis y desarrollo de los conceptos fundamentales de su pensamiento (como ejemplo concreto: del concepto "revelación trascendental"), $c f$. R. A. Siebenrock, “'Transzendentale Offenbarung'. Bedeutungsanalyse eines Begriffs im Spätwerk Rahners als Beispiel methodisch geleiteter Rahnerforschung", Zeitschrift für katholische Theologie 126 (2004) 33-46. 
llamar al hombre a lo más propio de su ser" (99). La mirada ignaciana de la existencia humana como historia personal que acontece ante Cristo y con Él, y que implica así la confianza creyente tanto en la acción transformadora y sanante de Dios como en que ello puede ocurrir desde dentro del actuar personal históricamente situado, es una invitación al cristiano a una respuesta integradora existencial a Dios, como un "contemplativo en la acción", es decir, como un permanente interrogador de sí mismo, de sus opciones y de su situación histórica, en su inevitable ambivalencia como posible llamado divino u ocasión de alienación, en la búsqueda de Dios que se da e interpela.

La praxis del cristiano, en clave ignaciana, ha de ser la praxis del que "busca a Dios en todas las cosas y a todas las cosas en Dios", esto es: del que busca en una existencia histórica responsable y siempre abierta -sin recetas absolutas o preestablecidas, pero a la vez asumiendo el contexto comunitario-tradicional de su opción-, en actitud de discernimiento. Un enfoque trascendental rahneriano de la reflexión teológica sobre la praxis puede ser, así, un valioso aporte a la Iglesia como la comunidad de los cristianos que peregrina por la historia buscando los signos del Reino de Dios para cuyo servicio existe. En esta búsqueda, una actitud permanente de discernimiento, personal y eclesial, será siempre una contribución decisiva para una respuesta más pura de la libertad humana a la interpelación del Dios que, en Jesús, ha querido salvar a la humanidad desde ella misma. Una praxis discernida a la luz del Evangelio será siempre una praxis esperanzada y disponible a que el designio salvador de Dios se realice desde y con la humanidad y no "por encima" de ella.

\section{RESUMEN}

La conmemoración del $40^{\circ}$ aniversario del Concilio Vaticano II (1962-1965) es una ocasión propicia para releer sus enseñanzas e intuiciones fundamentales y evaluar su recepción en el pensamiento y en la vida de la Iglesia. El artículo se propone aportar a esta tarea con una aproximación al tema de la praxis en sintonía con la doctrina de la constitución Gaudium et spes sobre la actividad humana en el mundo (GS 33-39). En ese espíritu, el artículo ofrece una presentación del método antropológico-trascendental del teólogo alemán Karl Rahner (19041984) como un camino de lectura teológica del mundo y de la praxis histórica relevante para los cristianos de hoy. Sitúa dicho método en el programa rahneriano de un "recentramiento antropológico" de la teología (1.) y explica su enfoque "trascendental" a la luz de su subyacente apertura al mundo moderno (2.); analiza someramente las diversas líneas que constituyen su sustrato filosófico (3.) y lo confronta con otro enfoque trascendental relevante como es el del filósofo francés Maurice Blondel (4.), para concluir con algunas reflexiones y perspectivas.

\section{ABSTRACT}

The commemoration of the $40^{\text {th }}$ anniversary of the Vatican Council II (1962-1965) is a suitable occasion to go over its fundamental teaching and institutions again and assess their

(99) M. Chojnacki, "Erhelende Rückführung...", 183. Cf. etiam A. Zahlauer, Karl Rahner und sein "produktives Vorbild" Ignatius von Loyola, Innsbruck 1996 y K. P. Fischer, "Gott als das Geheimnis des Menschen“ (ref. supra, nota 5). 
acceptance to the thought and life of the Church. This article attempts to make a contribution, presenting new lights on the issue of the praxis along with the doctrine of the Constitution Gaudium et Spes on the human activity in the world (GS 33-39). The article presents Karl Rahner's (1904-1984) anthropologic-transcendental method as a theological reading of the world and the historical praxis significant for modern Christians. The author sets this method within Rhaner's program of an 'anthropological re-centering' of theology. Thus he (1) explains his 'transcendental' approach in the light of the opening of the new world, (2) analyses the various lines underlying Rhaner's philosophical foundations, (3) contrasts them with another relevant transcendental approach, namely the one by the French Philosopher Maurice Blondel, to (4) end up with some reflections and projections on the issue. 